\title{
The Plant Growth-Promoting Rhizobacterium Bacillus cereus AR156 Induces Systemic Resistance in Arabidopsis thaliana by Simultaneously Activating Salicylate- and Jasmonate/Ethylene-Dependent Signaling Pathways
}

\author{
Dong-Dong Niu, ${ }^{1}$ Hong-Xia Liu, ${ }^{1}$ Chun-Hao Jiang, ${ }^{1}$ Yun-Peng Wang, ${ }^{1}$ Qing-Ya Wang, ${ }^{2}$ Hai-Ling Jin, ${ }^{3}$ and \\ Jian-Hua Guo ${ }^{1}$ \\ ${ }^{1}$ Department of Plant Pathology, College of Plant Protection, Nanjing Agricultural University; Engineering Center of \\ Bioresource Pesticide in Jiangsu Province; Key Laboratory of Monitoring and Management of Crop Diseases and Pest \\ Insects, Ministry of Agriculture; Nanjing 210095, China; ${ }^{2}$ College of Life Sciences, Nanjing Agricultural University, Nanjing \\ 210095, China; ${ }^{3}$ Department of Plant Pathology and Microbiology, Center for Plant Cell Biology and Institute for Integrative \\ Genome Biology, University of California, Riverside, CA 92521 U.S.A.
}

Submitted 22 September 2010. Accepted 27 December 2010.

\begin{abstract}
Bacillus cereus AR156 is a plant growth-promoting rhizobacterium that induces resistance against a broad spectrum of pathogens including Pseudomonas syringae pv. tomato DC3000. This study analyzed AR156-induced systemic resistance (ISR) to DC3000 in Arabidopsis ecotype Col-0 plants. Compared with mock-treated plants, AR156treated ones showed an increase in biomass and reductions in disease severity and pathogen density in the leaves. The defense-related genes PR1, PR2, PR5, and PDF1.2 were concurrently expressed in the leaves of AR156treated plants, suggesting simultaneous activation of the salicylic acid (SA)- and the jasmonic acid (JA)- and ethylene (ET)-dependent signaling pathways by AR156. The above gene expression was faster and stronger in plants treated with AR156 and inoculated with DC3000 than that in plants only inoculated with DC3000. Moreover, the cellular defense responses hydrogen peroxide accumulation and callose deposition were induced upon challenge inoculation in the leaves of Col-0 plants primed by AR156. Also, pretreatment with AR156 led to a higher level of induced protection against DC3000 in Col-0 than that in the transgenic NahG, the mutant jarl or etr1, but the protection was absent in the mutant npr1. Therefore, AR156 triggers ISR in Arabidopsis by simultaneously activating the SA- and JA/ET-signaling pathways in an NPR1dependent manner that leads to an additive effect on the level of induced protection.
\end{abstract}

To survive a hostile environment, plants have evolved a variety of inducible defense mechanisms that enable them to activate appropriate defense responses upon pathogen attack. Well-studied examples of induced resistance include systemic acquired resistance (SAR) and phenotypically similar rhizobacteria-induced systemic resistance (ISR); both SAR and ISR function systemically throughout the plant (Conrath et al. 2002). While SAR is triggered by necrotizing pathogens (Conrath et

Corresponding author. J.-H. Guo; E-mail: jhguo@njau.edu.cn; Telephone: +86-25-84395312; Fax: +86-25-84395425. al. 2002), ISR is activated by selected nonpathogenic rhizobacteria, such as specific plant growth-promoting rhizobacteria (PGPR) (Van der Ent et al. 2009).

The phytohormones salicylic acid (SA), jasmonic acid (JA), and ethylene (ET) play crucial roles in the signaling network regulating the development of SAR and ISR (Glazebrook 2001). SAR is controlled by the SA-dependent signaling pathway, and its onset involves local and systemic increases in endogenously synthesized SA leading to activation of the regulatory protein NPR1 and the subsequent NPR1-dependent expression of genes encoding pathogenesis-related (PR) proteins, including PR1, PR2, and PR5 (Van Loon and Van Strien 1999; Ward et al. 1991). ISR is regulated by the JA/ET-dependent signaling pathway and is associated with the expression of the gene encoding plant defensin 1.2 (PDF1.2) (Van Oosten et al. 2008). Pieterse and associates (1998) reported that the ISR triggered by Pseudomonas fluorescens WCS417r was blocked in the Arabidopsis jasmonate response mutant jarl, the ethylene response mutant $e t r l$, and the nonexpresser of $P R$ genes mutant nprl. This demonstrates that WCS 417r-mediated ISR is dependent on the JA/ET-signaling pathway and NPR1.

Rhizobacteria-mediated ISR has been demonstrated in a variety of plants including bean, carnation, cucumber, radish, tobacco, tomato, and the model plant Arabidopsis thaliana (Van Loon et al. 1998). Beneficial rhizobacteria trigger ISR by priming the plant for potentiated activation of various cellular defense responses, which are subsequently induced upon pathogen attack (Conrath et al. 2006). The potentiated responses include the oxidative burst (Iriti et al. 2003), cell-wall reinforcement (Benhamou et al. 1996), accumulation of defenserelated enzymes (Benhamou and Belanger 1998), and production of secondary metabolites (Yedidia et al. 2003).

We previously isolated a rhizobacterium Bacillus cereus AR156. It was shown to significantly inhibit the leaf speck disease caused by Pseudomonas syringae pv. tomato (Okabe, 1933) Young, Dye \& Wilkie, 1978, the bacterial wilt caused by Ralstonia solanacearum (Smith 1986) Yabuuchi et al. 1996, the blight caused by Phytophthora capsici Leon., and the rootknot disease caused by Meloidogyne incognita (Kofoid \& White) in tomato and some other vegetables (Guo et al. 2007). 
Thus, AR156 is a promising biocontrol agent against a broad spectrum of pathogens. The present study had three objectives: i) to assess AR156-induced protection against $P$. syringae pv. tomato DC3000 in Arabidopsis Col-0 plants; ii) to investigate the mechanism of AR156 priming for potentiated activation of the cellular defense responses hydrogen peroxide accumulation and callose deposition; and iii) to identify one or more signaling pathways involved in AR156-mediated ISR by analyzing expression patterns of SA-responsive $P R 1, P R 2$, and $P R 5$ genes and the JA/ET-responsive PDF1.2 gene in Arabidopsis Col-0, the transgenic NahG (a SA-nonaccumulating line expressing bacterial $\mathrm{NahG}$ ), and the mutants jarl, etrl, and $n p r l$.

\section{RESULTS}

\section{Bacillus sp. strain AR156 triggers ISR} to $P$. syrinage $\mathrm{DC} 3000$ in Arabidopsis.

Bacillus sp. strain AR156 was tested for its capacity to trigger ISR to $P$. syrinage DC3000 in Arabidopsis Col-0 plants in a greenhouse experiment, in which $P$. fluorescens WCS417r and benzothiadiazole (BTH) were employed to trigger ISR and SAR, respectively, as positive controls. Besides necrotizing pathogens, exogenous application of SA or its functional analogs, such as BTH, also induces SAR (Conrath et al. 2002). Five days after DC3000 inoculation, mock-treated plants showed typical symptoms of bacterial speck disease-the leaves with yellowing or water-soaked spots surrounded by extensive chlorosis (Fig. 1A). However, AR156-treated plants exhibited a significant $(P<0.05)$ reduction in disease severity compared with mock-treated plants; accordingly, the efficacy of AR156 in controlling the leaf speck disease caused by DC3000 reached $50.5 \%$ (Fig. 1A and B). The efficacy of WCS417r and BTH in controlling the same disease attained to 47.1 and $46.2 \%$, respectively (Fig. 1B). In addition, 5 days after DC3000 inoculation, the density of DC3000 in the leaves decreased by $86.5,82.3$, and $79.1 \%$ in plants treated with AR156, WCS417r, and BTH, respectively, compared with mock-treated plants (Fig. 1C).

\section{AR156 promotes growth of Arabidopsis.}

AR156 was assessed for its ability to promote the growth of Arabidopsis Col-0 plants in a greenhouse experiment. At 30 days after treatment, AR156-treated plants exhibited increases in shoot weight, root weight, biomass, and seed production by $68.8,57.2,67.4$, and $34.8 \%$, respectively, compared with mocktreated plants (Fig. 2A and B). The rhizosphere colonization of Arabidopsis Col-0 by AR156 was also monitored. The density of AR156 in the rhizosphere of Col-0 plants treated with AR156 ranged from $10^{6}$ to $10^{7} \mathrm{CFU}$ per gram of rhizosphere soil over seven timepoints, $0,1,3,7,15,30$, and 70 days posttreatment (dpt) (Fig. 2C), but at the same set of timepoints, the density of AR156 in the leaves of these plants was below the detection limit at $10^{2} \mathrm{CFU}$ per gram of leaf (data not shown). This indicated that AR156 successfully and stably colonized the roots but not the leaves of Arabidopsis Col- 0 .
A Control/DC3000

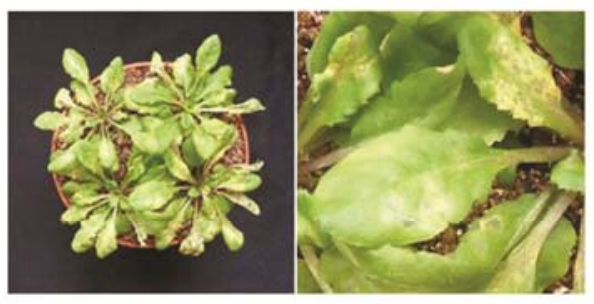

AR156/DC3000

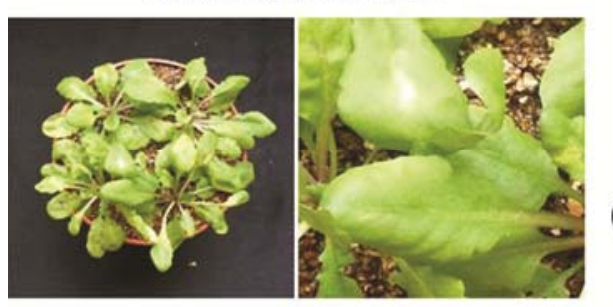

Control/Water

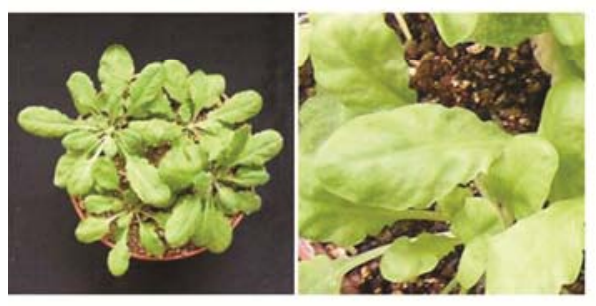

B
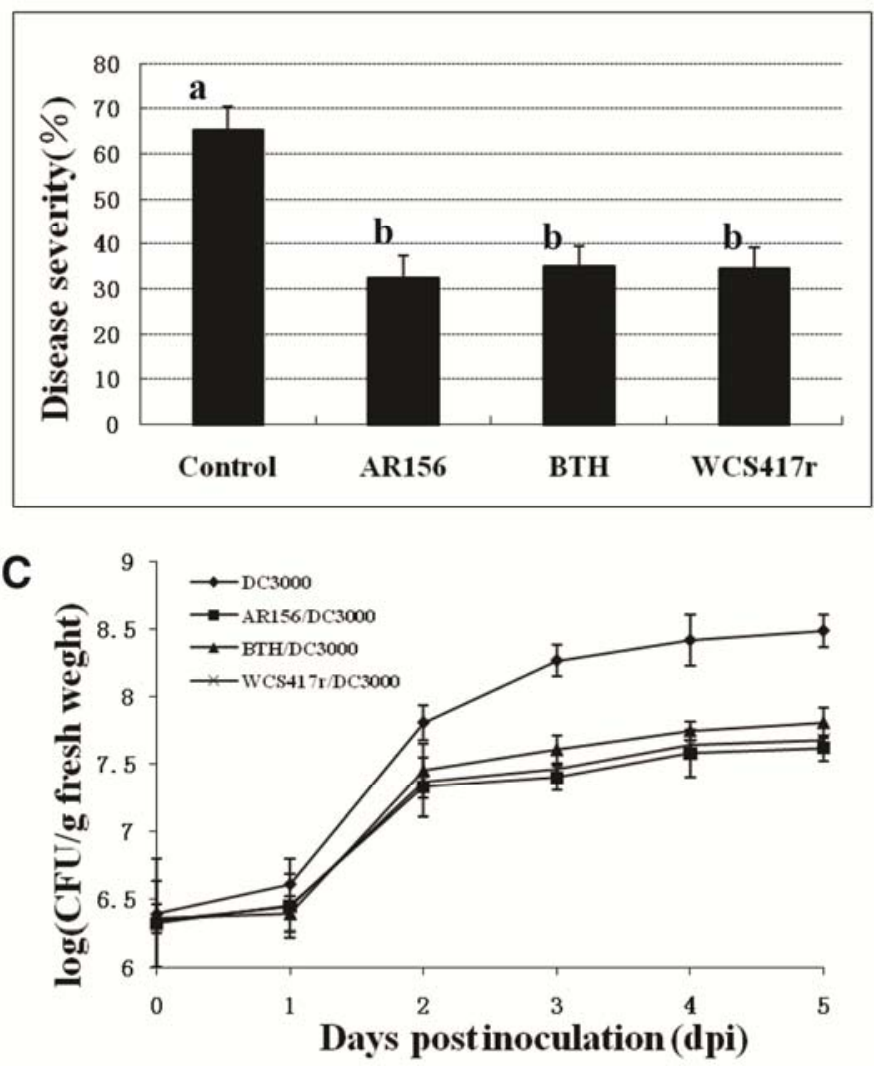

Fig. 1. Induction of systemic resistance to Pseudomonas syringae DC3000 in Arabidopsis Col-0 plants by Bacillus cereus AR156. Arabidopsis Col-0 plants were treated with AR156 at $5 \times 10^{8} \mathrm{CFU} / \mathrm{ml}, 1.2 \mathrm{mM} \mathrm{BTH}$, WCS417r at $5 \times 10^{8} \mathrm{CFU} / \mathrm{ml}$, and $0.85 \% \mathrm{NaCl}$, respectively. Five days later, leaves were sprayed with a cell suspension of DC3000 at $5 \times 10^{8} \mathrm{CFU} / \mathrm{ml}$. A, Representative plants of treatments of AR156, mock, and water control were photographed 5 days postinoculation (dpi). B, Disease severity of plants of each treatment was determined according to the disease index measured at 5 dpi (Pieterse et al. 1996). Values are means with standard errors from 24 plants. Different letters indicate statistically significant differences between treatments (least significant difference test; $P<0.05)$. C, Growth curves of DC3000 in the leaves of Arabidopsis plants of different treatments. Values are average numbers of CFU per gram of leaf, each from the leaves of nine individual plants of a treatment. All experiments were conducted three times with similar results. 
AR156 treatment and DC3000 inoculation induce defense-related gene expression in Arabidopsis.

Reverse-transcription polymerase chain reaction (RT-PCR) was used to analyze expression patterns of the defense-related genes PR1, PR2, PR5, and PDF1.2 in Arabidopsis Col-0 plants treated with AR156 alone. The transcription of these genes was evident in the leaves but not in the roots (Fig. 3A). Transcripts of all tested genes were accumulated in the leaves from 1 to $5 \mathrm{dpt}$, the amount of the PDF1.2 gene transcript peaked at $3 \mathrm{dpt}$, and transcripts of the three $P R$ genes reached their maximums at $4 \mathrm{dpt}$ (Fig. 3A). By contrast, the transcription of these genes was undetected in the leaves of mocktreated plants (Fig. 3A).

RT-PCR was also used to analyze the transcription of the four genes in Arabidopsis Col-0 plants only inoculated with DC3000 and in those treated with AR156 and inoculated with DC3000. Transcripts of all tested genes were detected from 12 to $48 \mathrm{~h}$ postinoculation (hpi) in the leaves of plants only inoculated with DC3000 but were detected from 6 to 48 hpi in those treated with AR156 and inoculated with DC3000, and PRI and $P D F 1.2$ gene transcripts attained their maximums at 24 hpi in the leaves of plants only inoculated with DC3000 but as soon as $12 \mathrm{hpi}$ in those treated with AR156 and inoculated with DC3000 (Fig. 3B). This indicated that the transcription of the four genes in plants treated with AR156 and inoculated with DC3000 was faster than that in plants only inoculated with DC3000. Furthermore, over all the timepoints, the transcription of the four genes was generally stronger in plants treated with AR156 and inoculated with DC3000 than that in plants only inoculated with DC3000 (Fig. 3B).

\section{AR156 primes for hydrogen peroxide accumulation and callose deposition in Arabidopsis.}

AR156 was examined for the mechanism of priming for potentiated activation of cellular defense responses in Arabidopsis Col-0 plants. Hydrogen peroxide accumulation and callose deposition were detected at $12 \mathrm{hpi}$ in the leaves of plants treated with AR156 and inoculated with DC3000, but neither
AR156 treatment nor DC3000 inoculation alone resulted in these cellular defense responses at the same timepoint (Fig. 4). On the other hand, at $24 \mathrm{hpi}$, these defense responses were also observed in plants only inoculated with DC3000 but were still not observed in those treated with AR156 alone (Fig. 4).

AR156-mediated ISR is dependent on the SAand JA/ET-dependent signaling pathways and NPR1.

We compared levels of AR156-induced protection against DC3000 in wild-type Arabidopsis Col-0, the transgenic NahG, and the defense-signaling mutants jarl, etrl, and nprl. Pretreatment with AR156 led to a significant $(P<0.05)$ reduction in disease severity in all tested Arabidopsis plants except nprl, compared with the respective controls only inoculated with DC3000; the about $40 \%$ reduction in this parameter in Col- 0 plants was significantly $(P<0.05)$ larger than the around $30 \%$ reduction in NahG, jarl, or etrl plants (Table 1).

At 5 hpi, pretreatment with AR156 led to a significant $(P<$ $0.05)$ reduction in pathogen density in the leaves of all tested Arabidopsis plants except nprl compared with the respective controls only inoculated with DC3000, and the reduction in this parameter in Col-0 plants was significantly $(P<0.05)$ larger than that in NahG, jarl, or etrl plants (Fig. 5A). The numbers of DC3000 in the leaves of different Arabidopsis plants pretreated with AR156 were about $6 \times 10^{7} \mathrm{CFU}$ per gram of leaf for Col- $0 ; 8 \times 10^{7} \mathrm{CFU} / \mathrm{g}$ for NahG, jarl, or etrl, and $5 \times$ $10^{8} \mathrm{CFU} / \mathrm{g}$ for $n p r 1$. On the other hand, the number of AR156 in the rhizosphere of each tested line of Arabidopsis plants was around $5 \times 10^{6} \mathrm{CFU}$ per gram of rhizosphere soil (Fig. 5B), indicating that the uneven levels of induced disease resistance in the five lines of Arabidopsis plants were not caused by AR156 colonizing the roots of them to different extents.

To identify one or more signal transduction pathways involved in AR156-mediated ISR, we analyzed expression patterns of the PRI and the PDF1.2 gene in the leaves of Col-0, NahG, jarl, etrl, and nprl plants in response to AR156 treatment alone, to DC3000 inoculation alone, and to AR156 treatment combined with DC3000 inoculation. In response to

A

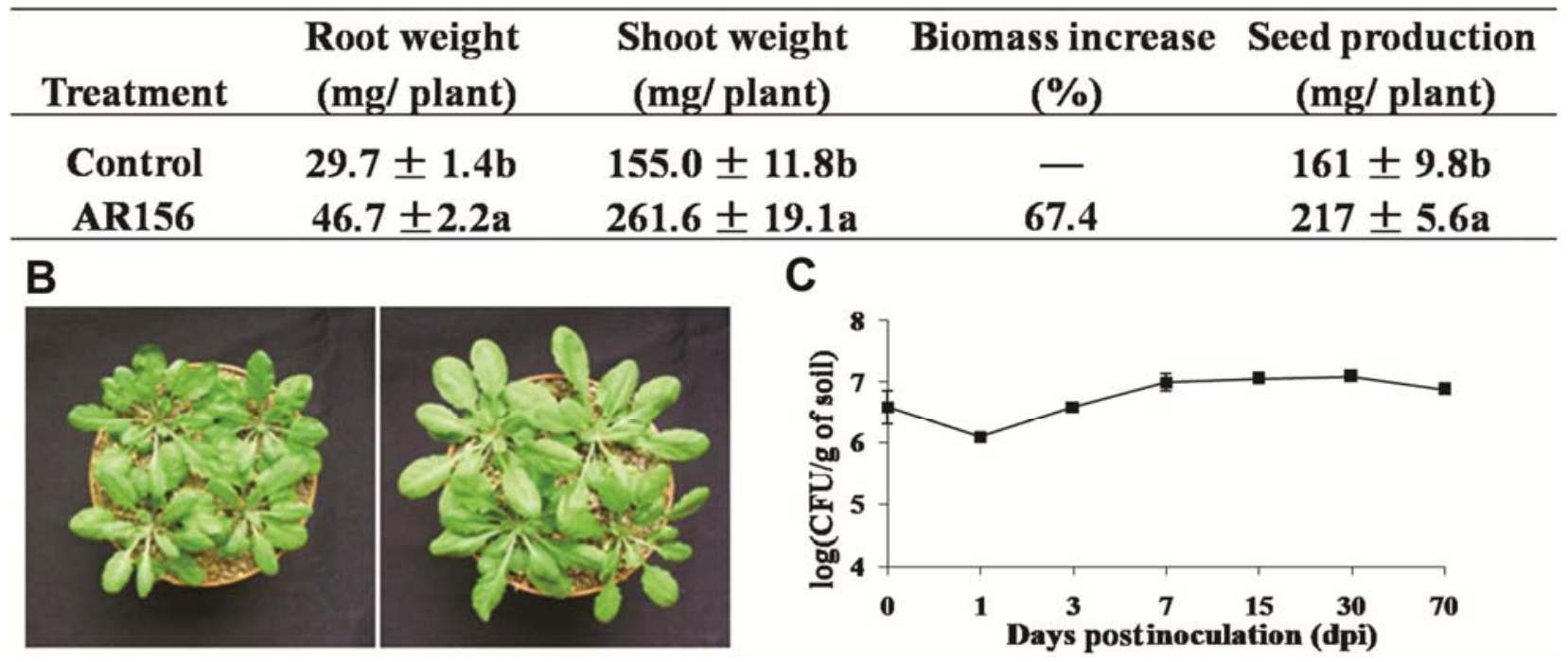

Fig. 2. Growth promotion and rhizosphere colonization of Arabidopsis Col-0 by AR156. Six-week-old Arabidopsis Col-0 plants were treated with a cell suspension of AR156 at $5 \times 10^{8} \mathrm{CFU} / \mathrm{ml}$ and $0.85 \% \mathrm{NaCl}$ in treatments of AR156 and control, respectively. Each treatment had 72 plants-24 for analysis of biomass, 24 for valuation of seed production, and 24 for examination of colonization. A, Root and shoot weights, increase in biomass, and seed production of each treatment. The increase in biomass is a sum of the rises in root weight and shoot weight. The data presented were from a representative experiment that was repeated three times with similar results. Different letters indicate statistically significant differences between treatments (Fisher's least significant difference; $P<0.05$ ). B, Representative plants of each treatment were photographed 30 days posttreatment. C, Timecourse of rhizosphere colonization of Arabidopsis by AR156. Data represent average numbers of CFU per gram of rhizosphere soil with standard deviation from three experiments. 
AR156 treatment alone, at $3 \mathrm{dpt}$, the $P R 1$ gene expression was evident only in Col-0, jarl, and etrl plants, while the PDF1.2 gene expression was detected only in Col-0 and NahG plants (Fig. 5C-1). Similar gene expression patterns were observed at 12 hpi in the corresponding Arabidopsis plants treated with AR156 and inoculated with DC3000. Meanwhile, the expression of the two genes was either very weak or undetected in plants only inoculated with DC3000 (Fig. 5C-2). Impressively, neither the $P R 1$ nor the $P D F 1.2$ was expressed in $n p r l$ plants in response to AR156 alone or when in combination with DC3000 (Fig. 5C-1 and C-2). These results suggested that AR156 treatment led to simultaneous activation of the SA- and JA/ET pathways in Col-0 plants, but to activation of the SApathway alone in jarl and etrl plants, the JA/ET-pathway alone in NahG plants, and to activation of neither pathway in nprl plants.

In addition, AR156 priming for activation of cellular defense responses was investigated in the five lines of Arabidopsis plants. A combination of AR156 treatment and DC3000 inoculation led to hydrogen peroxide accumulation and callose deposition in the leaves of Col-0, NahG, jarl, and etrl plants, but not nprl plants, while DC3000 inoculation alone did not result in these responses in all tested plants (Fig. 5D).

\section{DISCUSSION}

Although biological control is one of the most optimistic methods for plant protection, at present, the commercialization of biocontrol agents is still limited (Szewczyk et al. 2006), mainly due to complicated mechanisms of biocontrol that remain to be elucidated. We previously identified Bacillus cereus AR156 as a promising biocontrol agent (Guo et al. 2007). With the goal of commercializing AR156 in the future, we analyzed its biocontrol mechanism in this study by investigating AR156-mediated ISR to P. syringae DC3000 in the model plant Arabidopsis thaliana at phenotypic, cellular, and molecular levels.

Applying AR156 to the roots of Arabidopsis Col-0 plants produced effects of reducing disease severity and inhibiting pathogen proliferation in the leaves (Fig. 1), although AR156 only colonized the roots but not the leaves (Fig. 2C). This indicated that AR156 induced systemic resistance to DC3000 in Arabidopsis; therefore, AR156 is an ISR-inducing rhizobacterium. In addition, AR156-treated plants exhibited statistically significant increases in biomass and seed production compared with mock-treated plants (Fig. 2A and B), suggesting that AR156 is a PGPR.

Rhizobacteria-mediated ISR is often associated with priming for enhanced activation of cellular defense responses (Van Wees et al. 2008), such as rapid accumulation of hydrogen peroxide and deposition of callose (Conrath et al. 2002), which are induced upon pathogen attack. Higher peroxidase activity and newly formed callose deposits were observed in Arabidopsis, tomato, and pigeon pea treated with rhizobacteria and inoculated with pathogens (Podile and Laxmi 1998; Silva et al. 2004). In this study, hydrogen peroxide accumulation and callose deposition were detected at 12 hpi in the leaves of Arabidopsis Col-0 plants treated with AR156 and inoculated with

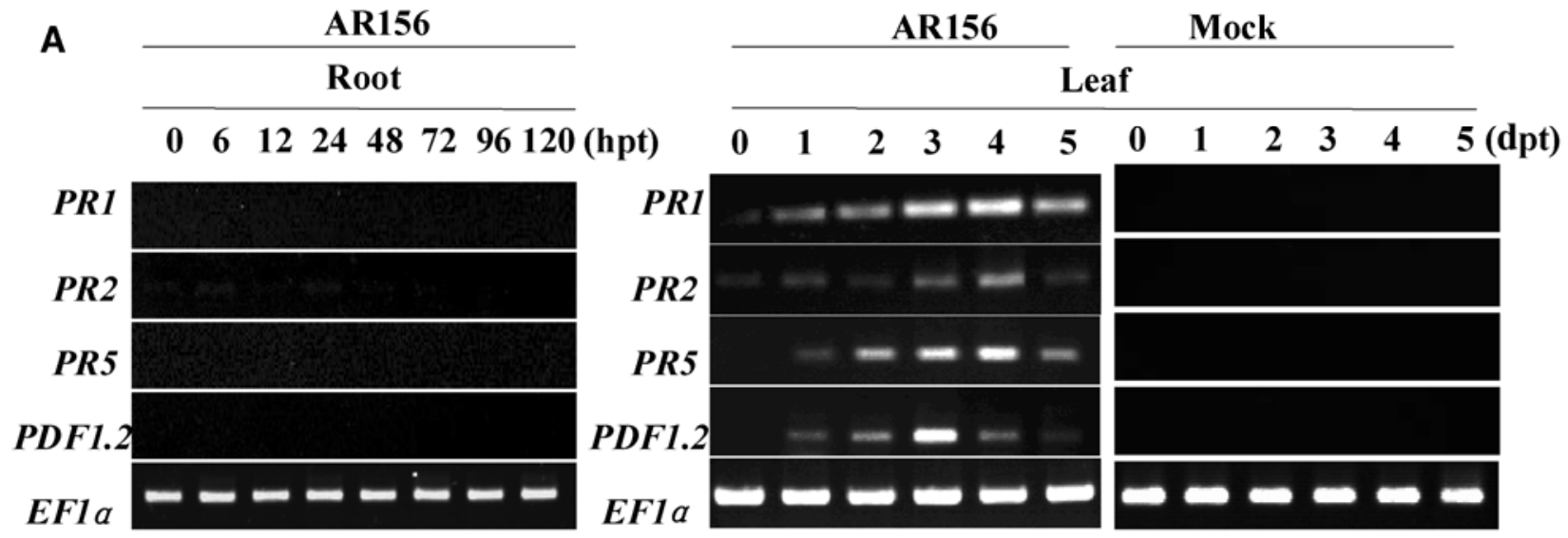

B Control/DC3000 AR156/DC3000

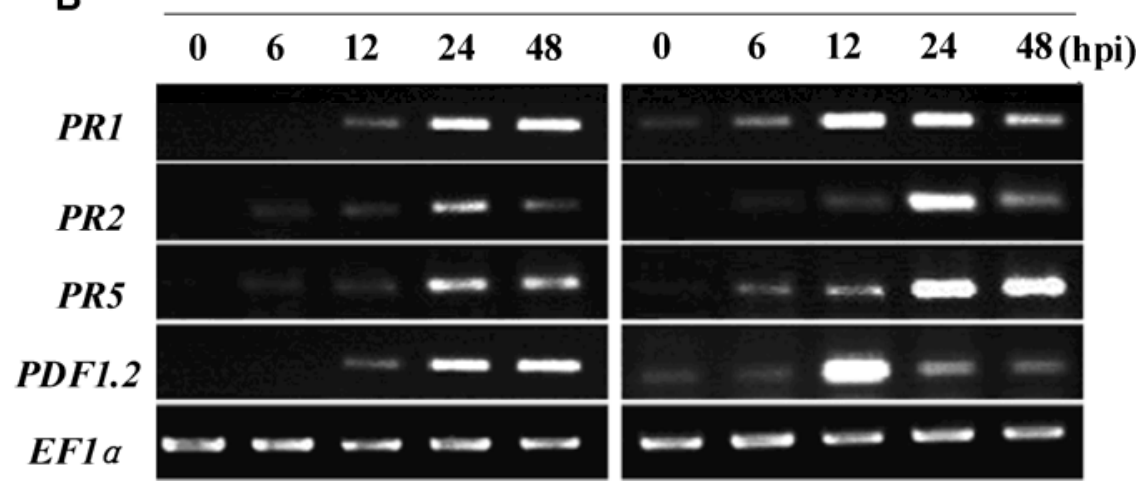

Fig. 3. Expression of $P R 1, P R 2, P R 5$, and PDF1.2 genes in Arabidopsis Col-0 plants in response to AR156 treatment or in combination with DC3000 inoculation. The roots and leaves of Arabidopsis Col-0 plants were harvested at indicated timepoints for extracting total RNA. dpt $=$ days posttreatment, hpt $=$ hours posttreatment, and hpi = hours postinoculation. A, Time course of the expression of PR1, PR2, PR5, and PDF1.2 genes in the roots and leaves of Arabidopsis Col-0 plants treated with AR156 alone and in the leaves of mock-treated Col- 0 plants. B, Time course of the expression of $P R 1, P R 2, P R 5$, and PDF1.2 genes in the leaves of Arabidopsis Col-0 plants treated with AR156 and inoculated with DC3000. 
DC3000 but not in those treated with AR156 or DC3000 alone and, at $24 \mathrm{hpi}$, the same responses were also observed in plants inoculated with DC3000 alone but still not in those treated with AR156 alone (Fig. 4). This implies that AR156 primes the plant for accelerated and enhanced capacity to activate cellular defense responses in systemic tissue, which are induced only upon pathogen attack. We infer that priming is an important mechanism underlying well-coordinated roles of AR156 in

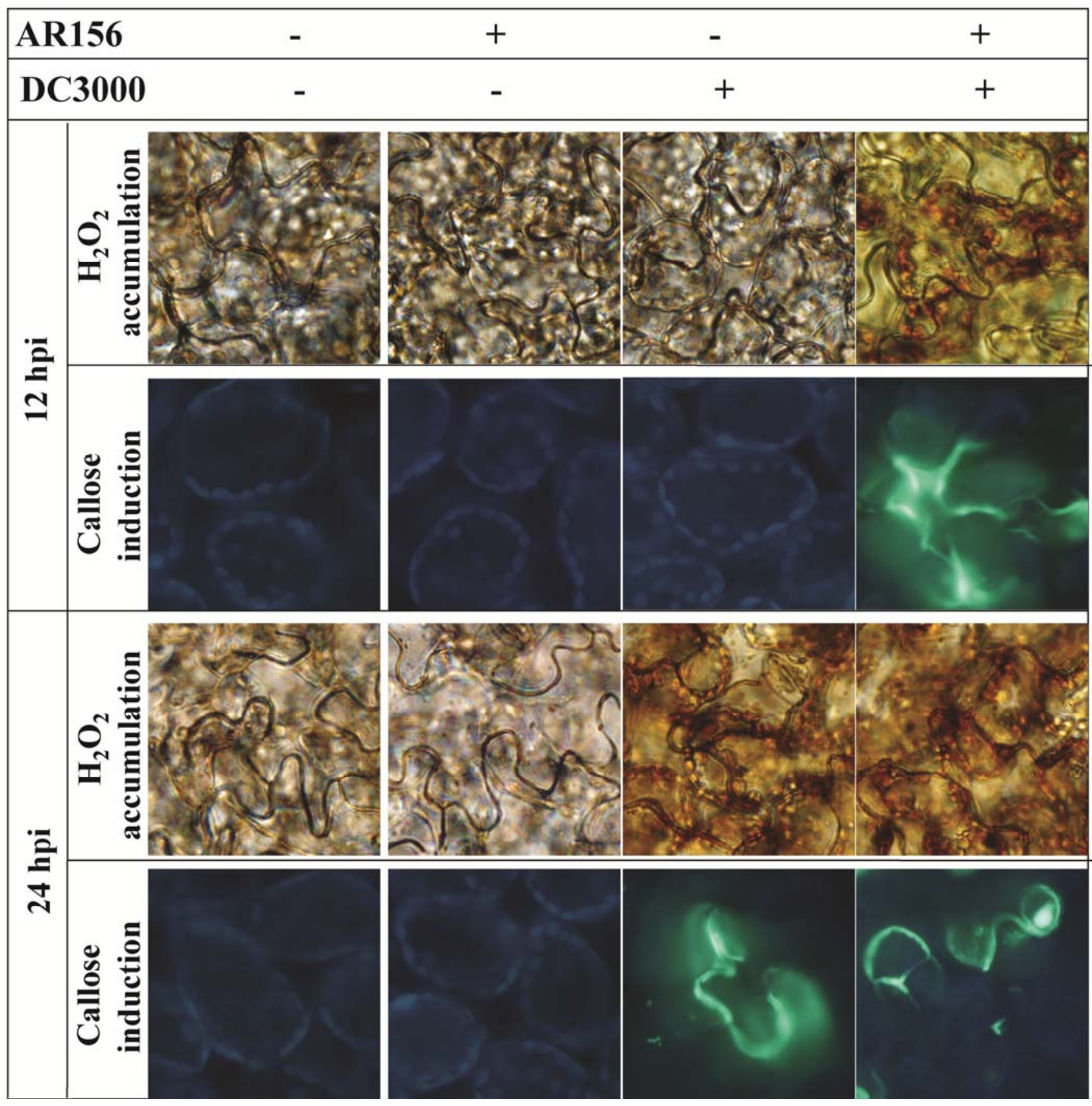

Fig. 4. AR156 priming for activation of hydrogen peroxide accumulation and callose deposition in the leaves of Arabidopsis Col-0 plants upon DC3000 attack. Arabidopsis Col-0 plants were inoculated with DC3000 at $5 \mathrm{dpt}$, and the leaves were sampled at 12 and 24 hpi. Hydrogen peroxide accumulation and callose deposition were observed under light and epifluorescence microscopes, respectively. All experiments were performed three times and similar results were obtained.

Table 1. Reduction in disease severity in Arabidopsis Col-0, NahG, jarl, etrl, and $n p r 1$ plants treated with AR156 ${ }^{\mathrm{a}}$

\begin{tabular}{lccccc}
\hline Treatment & Col-0 & NahG & jarl & etrl & nprl \\
\hline Control & $69.1 \pm 4.0 \mathrm{c}$ & $70.2 \pm 4.6 \mathrm{c}$ & $70.4 \pm 1.6 \mathrm{c}$ & $73.2 \pm 3.4 \mathrm{c}$ & $73.5 \pm 1.0 \mathrm{c}$ \\
AR156 & $30.2 \pm 4.5 \mathrm{a}$ & $37.4 \pm 2.2 \mathrm{~b}$ & $36.6 \pm 1.6 \mathrm{~b}$ & $38.9 \pm 3.8 \mathrm{~b}$ & $72.6 \pm 1.7 \mathrm{c}$ \\
\hline
\end{tabular}

${ }^{a}$ Arabidopsis plants were treated with a cell suspension of AR 156 at $5 \times 10^{8} \mathrm{CFU} / \mathrm{ml}$ or $0.85 \% \mathrm{NaCl} ; 5$ days later, the leaves were sprayed with DC3000 at $5 \times$ $10^{8} \mathrm{CFU} / \mathrm{ml}$. Values are means of disease severity with standard errors from 24 plants in a representative experiment that was repeated three times with similar results. Rating was performed 5 days after DC3000 inoculation. Different letters indicate statistically significant differences between treatments (least significant difference test, $P<0.05$ ). 
A

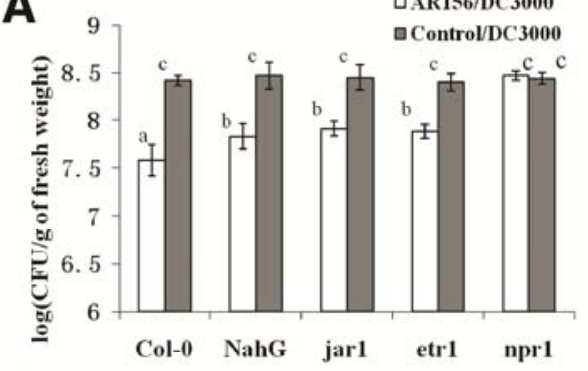

C-1

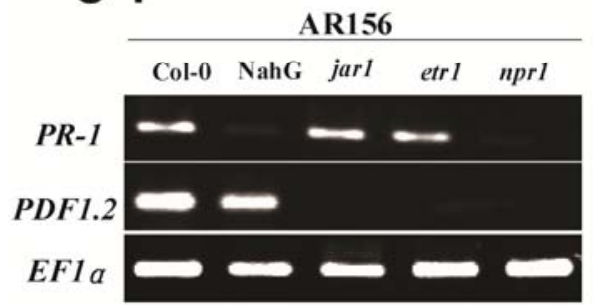

D
B

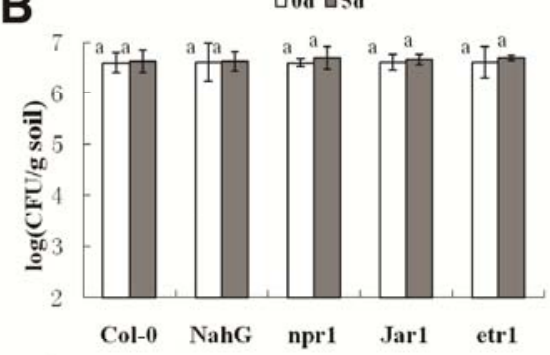

C-2

Control/DC3000 AR156/DC3000 Col-0 NahG jarl etrl nprl Col-0 NahG jarl etrl nprl PR-1

PDF1.2 EF1a

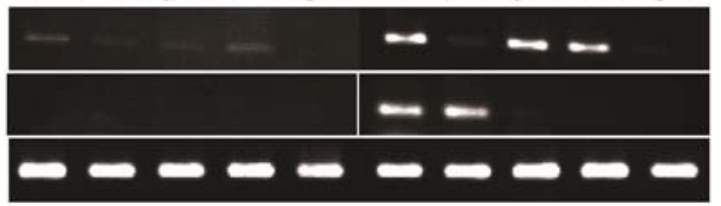

\section{$\mathrm{H}_{2} \mathrm{O}_{2}$ accumulation}

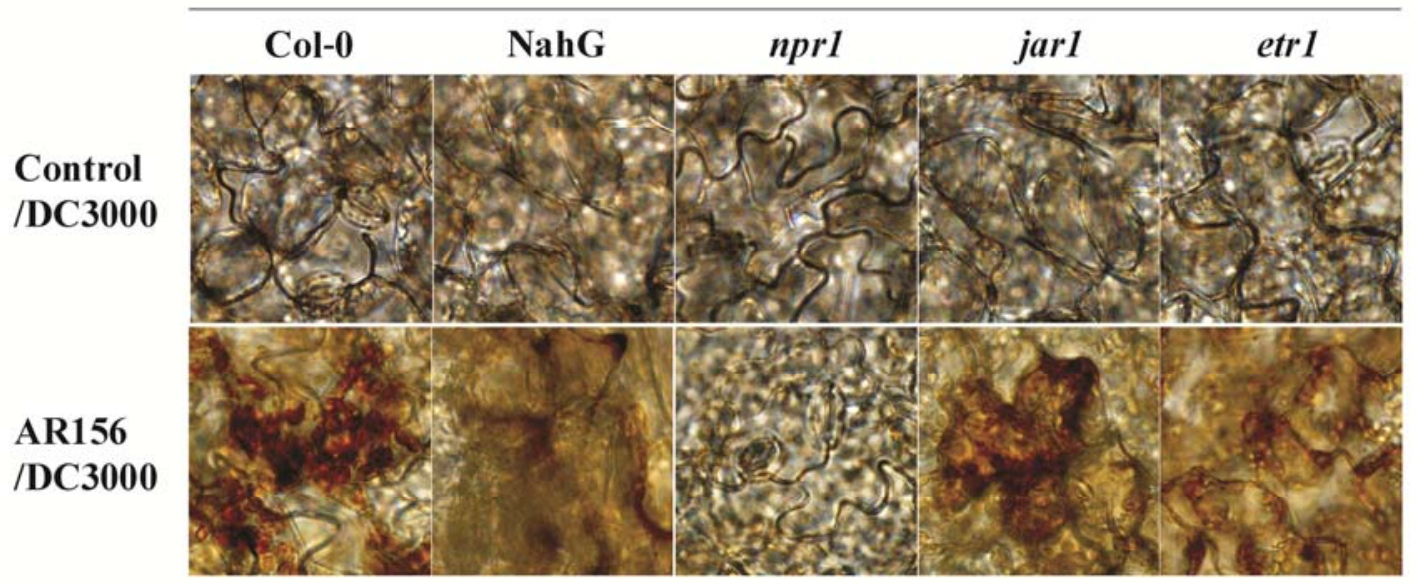

Callose induction

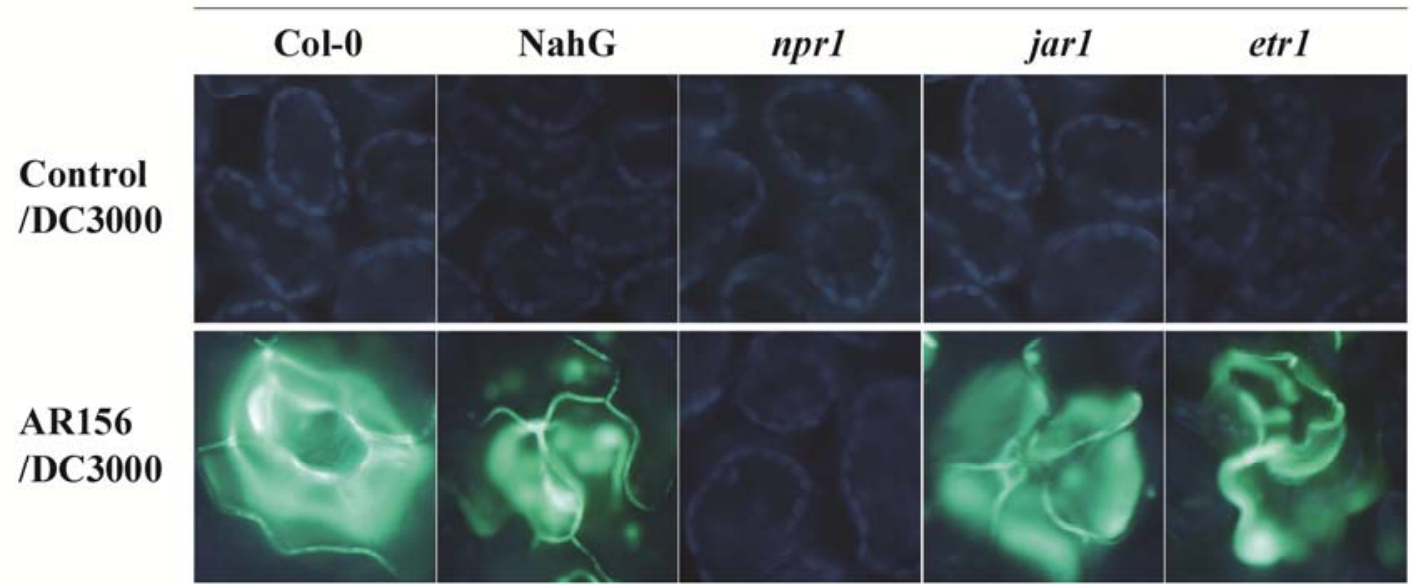

Fig. 5. AR156-mediated induced systemic resistance to DC3000 in Arabidopsis Col-0, NahG, etrl, jarl, and nprl plants at phenotypic, cellular, and molecular levels. A, DC3000 density in the leaves of Arabidopsis plants. Plants were inoculated with DC3000 at 5 days posttreatment (dpt), and leaves were harvested at 5 days postinoculation. Bars represent average numbers of CFU per gram of leaf fresh weight. Different letters indicate statistically significant differences between treatments (least significant difference test [LSD]; $P<0.05$ ). B, Rhizosphere colonization of Arabidopsis by AR156. Rhizosphere samples were collected at $5 \mathrm{dpt}$, and the number of CFU of kanamycin-resistant AR156 was estimated. Different letters indicate statistically significant differences between treatments (LSD test; $P<0.05$ ). C, Expression of $P R 1$ and PDF1.2 genes in the leaves of Arabidopsis plants treated with AR156 alone (C-1) and of those treated with AR156 and inoculated with DC3000 (C-2). The leaves of Arabidopsis plants treated with AR156 alone and of those treated with AR156 and inoculated with DC3000 were harvested at $3 \mathrm{dpt}$ and $12 \mathrm{~h}$ postinoculation (hpi), respectively, for extraction of total RNA. D, Hydrogen peroxide accumulation and callose deposition in the leaves of Arabidopsis plants inoculated with DC3000 alone and of those treated with AR156 and inoculated with DC3000. Plants were inoculated with DC3000 at $5 \mathrm{dpt}$, and leaves were sampled at $12 \mathrm{hpi}$. 
activating ISR and promoting plant growth. Both plant growth and activation of inducible defense responses consume energy. However, plants primed by AR156 do not invest energy in activating cellular defense responses before pathogen attack, thus avoiding unnecessary consumption of energy that plants divert to other important metabolic processes, such as growth and reproduction.

It has been well established that there is cross-talk between the SA- and JA/ET-dependent signaling pathways (Koornneef and Pieterse 2008). This cross-talk acts as a cost-efficient regulatory mechanism by which the plant finely tunes its inducible defense responses to the type of attacker encountered (Kunkel and Brooks 2002). In most documented examples, the SA- and JA/ET-signaling pathways interact antagonistically-stimulating either one leads to the suppression of the other (Koornneef and Pieterse 2008). However, the results in this study suggest that AR156-mediated ISR to DC3000 in Arabidopsis does not involve this type of cross-talk. Although AR156 only stimulated the JA/ET-pathway in NahG plants and the SA-pathway in jarl and etrl plants (Fig. 5C), pretreatment with AR156 still led to activation of the cellular defense responses in the leaves of these plants upon challenge inoculation (Fig. 5D) and the resulting induced protection that was reflected in significant reductions in disease severity and pathogen density in the leaves (Table 1; Fig. 5A). On the other hand, AR156 simultaneously activated the SA- and JA/ET-signaling pathways in Arabidopsis Col-0 plants (Figs. 3 and 5C); pretreatment with AR156 resulted in a higher level of induced protection in Col0 plants than that in NahG, jarl, or etrl plants (Table 1; Fig. 5A). These results implicate that AR156-mediated ISR to DC3000 in Arabidopsis is accomplished through parallel activation of the SA- and JA/ET-signaling pathways, which leads to an additive effect on the level of induced disease resistance. However, pretreatment with AR156 failed to prime for the cellular defense responses (Fig. 5D) and induce protection in nprl plants (Fig. 5A and B; Table 1), for nprl mutation abolished activation of both the SA- and JA/ET-pathways by AR156 (Fig. 5C). This suggests that activation of these pathways by AR156 is dependent on the regulatory protein NPR1.

Mur and associates (2006) observed that cotreatment with SA and JA at relatively low concentrations (typically 10 to 100 $\mu \mathrm{M})$ led to a synergistic effect on the transcription of the PRI and PDF1.2 genes in explants of Arabidopsis Col-0 and that cotreatment with the two hormones at relatively high concentrations resulted in an antagonistic effect. This suggests that the nature of the interaction between the SA- and JA-signaling pathways is dependent on the relative concentrations of these hormones. In addition, ET also plays a crucial role in the signaling network that regulates induced defense responses in the plant; in particular, ET was shown to enhance the $P R 1$ gene expression in response to SA (Lawton et al. 1994) and to modulate NPR1-dependent cross-talk between SA and JA (Leon-Reyes et al. 2009). Based on these facts and the parallel activation of the SA and JA/ET pathways shown in the present study, we hypothesize that, while synergistic and antagonistic interactions between the SA and JA/ET pathways are due to these three hormones at relatively low and high concentrations in the plant, respectively, parallel (or simultaneous) activation of the two pathways occurs when the plant contains relatively moderate concentrations of these hormones. We speculate that treatment with AR156 may lead to moderate levels of SA, JA, and ET synthesized in Arabidopsis Col-0 plants, moderately activating the SA and JA/ET pathways in parallel bringing an additive level of resistance to DC3000. In fact, this hypothesis is in agreement with our results that, although BTH and WCS417r only stimulate the SA and the JA/ET pathways, respectively, the level of induced protection in AR156-treated plants was not significantly higher than that in BTH- or WCS417r-treated plants (Fig. 1B). We infer that treatment with AR156 might activate the SA-pathway to a lower extent than treatment with BTH at $1.2 \mathrm{mM}$ (a relatively high concentration) and that treatment with AR156 might stimulate the JA/ ET-pathway to a lower extent than treatment with WCS417r.

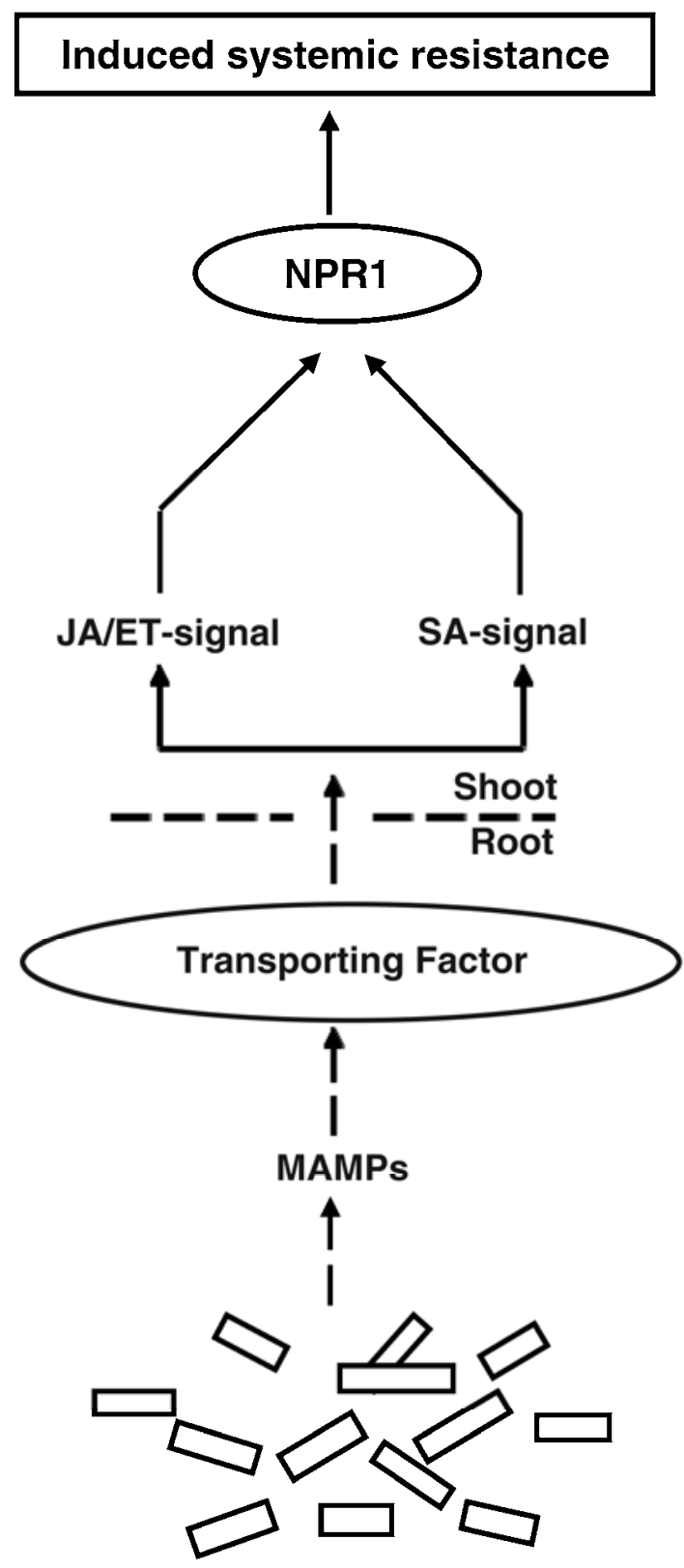

\section{Bacillus cereus AR156}

Fig. 6. Model of the signal transduction cascade of AR156-mediated induced systemic resistance (ISR) from the roots to leaves of Arabidopsis. Recognition of unique mitogen-associated molecular patterns (MAMPs) of AR156 by the receptors of Arabidopsis leads to the generation of a distinct ISR signal in the roots, in which it does not elicit defense responses. Its mobilization from the roots to the shoots triggers ISR in the leaves by simultaneously activating the salicylic acid (SA)- and the jasmonic acid (JA)- and ethylene (ET)-dependent signaling pathways in an NPR1-dependent manner there, which leads to concurrent expression of a large set of the SA- and JA/ET-responsive genes in the leaves. Induction of ISR is associated with priming for robust cellular defense responses, which are subsequently activated in the leaves upon pathogen attack. Parallel activation of the SA and JA/ET pathways by AR156 leads to an additive effect on the level of induced protection. 
However, simultaneous activation of the two pathways at moderate levels by AR156 produced an additive effect on induced resistance against DC3000 in the plant, which reached a level statistically similar to that resulting from a stronger activation of the SA pathway alone by BTH or the JA/ET pathway alone by WCS417r.

Van Wees and associates (2000) also observed that activation of both the SA- and JA/ET-signaling pathways in Arabidopsis Col-0 plants led to a higher level of induced protection against $P$. syringae pv. tomato DC3000 than that obtained by stimulation of either pathway alone. However, there is a fundamental difference between their findings and ours. In their experiment, the enhancement of induced protection resulted from activation of the SA- and the JA/ET-signaling pathways by an avirulent $P$. syringae DC3000 or $P$. fluorescens WCS417r, respectively, whereas AR156 alone simultaneously activating the two pathways led to a similar additive effect. Like WCS417r-meditaed ISR, many documented examples of ISR triggered by different rhizobacteria are only dependent on the JA/ET-signaling pathway but independent of the SA-signaling pathway (Ahn et al. 2007; Ryu et al. 2003).

It has been reported that interactions between the receptors of Arabidopsis and microbe-associated molecular patterns (MAMPs) of beneficial rhizosphere-colonizing microorganisms, such as P. fluorescens WCS417r and the fungus Trichoderma asperellum T34, leads to local expression of the transcription factor MYB72 in the roots (Segarra et al. 2009; Van der Ent et al. 2008). It is assumed that the interaction between MYB72 and another signaling component in the roots is necessary for the onset of ISR in the leaves (Van Wees et al. 2008). On the other hand, P. fluorescens_WCS417r suppresses MAMP-elicited defense responses in Arabidopsis roots, such as deposition of callose in the root elongation zone elicited by the flagellar peptide Flg22 (Millet et al. 2010). In the present study, applying AR156 to Arabidopsis roots resulted in the expression of four defense-related genes (PR1, PR2, PR5, and PDF1.2) in the leaves but not in the roots (Fig. 3A), whereas AR156 was absent in the leaves. Similarly, root inoculation with Bacillus subtilis FB17 resulted in the expression of PRI and PDF1.2 in Arabidopsis leaves but not in the roots (Rudrappa et al. 2010). The results suggest that these beneficial microorganisms actively block immune responses in Arabidopsis roots in order to avoid being recognized as 'nonself' and establish a compatible interaction with their host, which may be important for root colonization by them. Accordingly, AR156 suppressing defenserelated gene expression in Arabidopsis roots might contribute to the stable root colonization by it (Fig. 2C). Here, we also propose a model of the signal transduction cascade of AR156-mediated ISR from the roots to leaves of Arabidopsis (Fig. 6). Presumably, there are some differences between the MAMPs of AR156 and those of the rhizobacteria triggering JA/ET-dependent ISR, such as WCS417r. We hypothesize that the unique MAMPs of AR156 are recognized by the receptors of Arabidopsis, leading to a distinct ISR signal generated in the roots. The signal does not elicit defense responses in the roots, but its mobilization from the roots to the leaves triggers ISR in the leaves by simultaneously activating the SA- and JA/ET-signaling pathways in an NPR1-dependent manner, which produces an additive effect on the level of induced disease resistance.

To the best of our knowledge, the present study is the first report that one PGPR triggers ISR via simultaneous activation of the SA- and JA/ET-signaling pathways resulting in an enhanced level of induced protection in Arabidopsis. In the further study, we will investigate how simultaneous activation of these pathways by AR156 leads to increased resistance against $P$. syringae DC3000. The knowledge in this aspect will be instrumental in improving the application of AR156 to plant protection.

\section{MATERIALS AND METHODS}

Plants, bacterial strains, and growth conditions.

Seeds of lines Col-0 (wild-type Arabidopsis thaliana ecotype), NahG (a transgenic line of Col-0 harboring the bacterial NahG gene) (Delaney et al. 1994), nprl (Bowling et al. 1994), etrl (Bleecker et al. 1988), and jarl (Staswick et al. 1992) were sown in vermiculite. Three-week-old seedlings were transferred into $200-\mathrm{ml}$ pots containing a vermiculite-potting soil mixture that had been autoclaved for $20 \mathrm{~min}$ at $120^{\circ} \mathrm{C}$ twice on two consecutive days. There were four seedlings in each pot. Plants were cultivated in a growth chamber with a 10 -h day $\left(200 \mu \mathrm{E} \mathrm{m}^{-2} \mathrm{~s}^{-1}\right.$ at $\left.24^{\circ} \mathrm{C}\right)$ and 14 -h night $\left(20^{\circ} \mathrm{C}\right)$ cycle at $70 \%$ relative humidity and supplied with modified halfstrength Hoagland nutrient solution (Hoagland and Arnon 1938) weekly.

The tested PGPR in this experiment is Bacillus cereus AR156, which was originally isolated from the forest soil of Zhenjiang City, Jiangsu Province, China. AR156-Ka, a kanamycin-resistant mutant of AR156, was grown on Luria-Bertani (LB) agar plates supplemented with $200 \mathrm{mg}$ of kanamycin per liter at $28^{\circ} \mathrm{C}$ for $24 \mathrm{~h}$. Subsequently, bacterial cells were pelleted by centrifugation and were resuspended in sterile $0.85 \%$ $\mathrm{NaCl}$, adjusting to $5 \times 10^{8} \mathrm{CFU} / \mathrm{ml}$ for use.

Nonpathogenic, ISR-inducing rhizobacterium $P$. fluorescens WCS417r (WCS417r) was grown on King's medium B (KB) agar plates at $28^{\circ} \mathrm{C}$ for $24 \mathrm{~h}$. Subsequently, bacterial cells were pelleted by centrifugation and were resuspended in sterile $0.85 \% \mathrm{NaCl}$, adjusting to $5 \times 10^{8} \mathrm{CFU} / \mathrm{ml}$ for use.

The challenging pathogen Pseudomonas syringae pv. tomato DC3000 was grown in liquid KB medium containing 50 $\mathrm{mg}$ of rifampicin per liter at $28^{\circ} \mathrm{C}$ overnight. Cultured DC3000 cells were pelleted by centrifugation, were washed once with and resuspended in $10 \mathrm{mM} \mathrm{MgSO}_{4}$ containing $0.01 \%$ ( $\mathrm{vol} / \mathrm{vol}$ ) of the surfactant Silwet L-77 (Sigma, St. Louis), and were adjusted to $5 \times 10^{8} \mathrm{CFU} / \mathrm{ml}$.

\section{Induction of systemic resistance.}

After growth in pots for 3 weeks, 6-week-old plants were subjected to induction treatments. There were five treatments, AR156, BTH, WCS417r, mock control, and water control. Each treatment had 24 plants. For treatment of AR156 or WCS417r, $10 \mathrm{ml}$ of a cell suspension of AR156-Ka or WCS417r at $5 \times 10^{8} \mathrm{CFU} / \mathrm{ml}$ was poured on the soil around the roots of Arabidopsis Col-0 plants in each pot. For BTH treatment, the roots of plants were treated with $1.2 \mathrm{mM} \mathrm{BTH}$ (Sigma-Aldrich), as described by Ahn and associates (2007). For two control treatments, an equal volume of sterile $0.85 \%$ $\mathrm{NaCl}$ was poured on the soil around the roots of Arabidopsis in each pot. Five days after induction treatment, plants of all treatments except water control were challenge-inoculated by spraying the leaves with a cell suspension of the virulent pathogen $P$. syringae DC3000 at $5 \times 10^{8} \mathrm{CFU} / \mathrm{ml}$ until all the leaves were covered with fine droplets. After challenge inoculation, all plants were kept in a dew chamber at $100 \%$ relative humidity for 3 days and were then transferred to a growth chamber. Five days after challenge inoculation, the disease index was assessed according to Hossain and associates (2007), and disease severity and biocontrol efficacy were calculated as follows.

Disease severity is the percentage calculated by the summation of all products of the number of diseased plants of the same index and the corresponding index, divided by the product of the total number of all diseased plants and the highest disease index. 
Biocontrol efficacy is the percentage calculated through the difference between the disease severity of the control and that of the rhizobacterium-treated group, divided by the disease severity of the control.

\section{Quantification of DC3000 in Arabidopsis leaves.}

To examine the density of DC3000 in Arabidopsis leaves, they were sampled at six timepoints, $0,1,2,3,4$, and 5 days postinoculation. Each leaf sample was weighed and soaked in $70 \%$ ethanol for $30 \mathrm{~s}$ for surface sterilization, was washed in sterile distilled water for $30 \mathrm{~s}$, and was then homogenized using a sterile pestle and mortar with $10 \mathrm{mM} \mathrm{MgSO}_{4}$. Subsequently, appropriate dilutions were plated onto $\mathrm{KB}$ agar supplemented with $50 \mathrm{mg}$ of rifampicin per liter and $100 \mathrm{mg}$ of cycloheximide per liter (Pieterse et al. 1996) and were incubated at $28^{\circ} \mathrm{C}$. After incubation for $48 \mathrm{~h}$, colonies of rifampicinresistant pathogen strain DC3000 on plates were counted, and DC3000 density in the leaves was thus determined and expressed as CFU per gram of leaf fresh weight (fw). This experiment was repeated four times. Mean comparison was conducted using a least significant difference (LSD) test $(P=0.05)$. Standard errors and LSD results were recorded.

\section{Assessment of plant-growth promotion.}

The ability of AR156 to promote plant growth was assessed in a greenhouse experiment consisting of two treatments with 48 plants per treatment. In AR156 treatment, the roots of Arabidopsis Col-0 plants were drenched with a cell suspension of AR156$\mathrm{Ka}$ at $5 \times 10^{8} \mathrm{CFU} / \mathrm{ml}$ as described above. In mock treatment, the roots were drenched with an equal volume of sterile $0.85 \%$ $\mathrm{NaCl}$. At 30 days after treatment, whole Arabidopsis Col-0 plants were collected for measuring fw of roots and shoots, and weight of seeds. This experiment was repeated three times.

\section{Quantification of AR156 within Arabidopsis rhizosphere and leaves.}

Three individual Arabidopsis Col-0 plants treated with AR156 were harvested for collecting the rhizosphere and leaf samples at each of the seven timepoints, $0,1,3,7,15,30$, and $70 \mathrm{dpt}$. The rhizosphere sample comprised total root systems and the tightly adhering soil. The leaf or rhizosphere samples from three plants were thoroughly mixed. To detach bacterial cells from the rhizosphere, $1 \mathrm{~g}$ of mixed rhizosphere sample (fw) was resuspended in $9 \mathrm{ml}$ of sterile $0.85 \% \mathrm{NaCl}$ and was vortexed for 5 min; also, $1 \mathrm{~g}$ of mixed leaf sample (fw) was ground with $9 \mathrm{ml}$ of the same solution. Serial dilutions of a cell suspension of the rhizosphere or leaf tissue were plated on LB medium supplemented with $200 \mathrm{mg}$ of kanamycin and $100 \mathrm{mg}$ of cycloheximide per liter. The number of CFU per gram of rhizosphere soil or leaf (fw) was determined after incubation at $28^{\circ} \mathrm{C}$ for 24 h. The experiment of detecting AR156 within Arabidopsis rhizosphere and leaves was repeated three times.

\section{Detection of hydrogen peroxide accumulation and callose deposition.}

To detect accumulation of hydrogen peroxide, Arabidopsis leaves were stained with $1 \mathrm{mg}$ of diaminobenzidine (DAB, $\mathrm{pH} 3.8$ ) per milliliter for $8 \mathrm{~h}$ under light at 25 to $37^{\circ} \mathrm{C}$. The DAB solution was then supplemented with $50 \mathrm{mM}$ ascorbic acid, a scavenger of hydrogen peroxide, to ensure the specificity of staining. Subsequently, leaves were cleared with $96 \%$ (vol/vol) ethanol and were preserved in $50 \%$ (vol/vol) ethanol. DAB staining visualizes hydrogen peroxide as red-brown precipitate under the light microscope.

To determine callose deposition, Arabidopsis leaves were sampled at $12 \mathrm{hpi}$ and were treated as described by Reuber and associates (1998) with a minor modification, i.e., for each line of Arabidopsis plants, two or three leaves were immerged in 5 $\mathrm{ml}$ of a destaining solution (phenol/glycerol/lactic acid/water/ ethanol $=1: 1: 1: 1: 8(\mathrm{vol} / \mathrm{vol} / \mathrm{vol} / \mathrm{vol} / \mathrm{vol}))$ in a bottle and were infiltrated by applying a vacuum for 5 to $10 \mathrm{~min}$. The bottle with samples was incubated in a $60^{\circ} \mathrm{C}$ water bath for 20 to 30 min to clear chlorophyll. The chlorophyll-free leaves were gently rinsed with water and were then soaked in 3 to $5 \mathrm{ml}$ of $0.01 \%$ (wt/vol) aniline blue stain containing $150 \mathrm{mM} \mathrm{K}_{2} \mathrm{HPO}_{4}$ ( $\mathrm{pH} 9.5$ ) in the dark for 2 to $4 \mathrm{~h}$. After staining, leaves were gently rinsed with water and were then mounted on microscope slides and were observed under an epifluorescence microscope with a UV excitation filter. This experiment was repeated three times.

\section{Analysis of gene expression by RT-PCR.}

To analyze the expression of $P R 1, P R 2, P R 5$, and PDF1.2 genes, RT-PCR was performed according to the manufacturer's instructions for the PrimeScript first-strand cDNA synthesis kit (TaKaRa Biotech, Dalian, China). Total RNA was extracted from Arabidopsis leaves using TRIzol reagent (Invitrogen, San Diego, CA, U.S.A.). Using the oligo dT primer, first-strand cDNA was synthesized from $500 \mathrm{ng}$ of total RNA. Independent PCR with 25 cycles was performed using aliquots $(1 \mu \mathrm{l})$ of cDNA samples and PR1-, PR2-, PR5- or PDF1.2-specific primers described by Dos Santos and associates (2003). A constitutively expressed gene, EF1 $\alpha$, was used as a quantitative control in the RT-PCR analysis.

\section{ACKNOWLEDGMENTS}

We thank Y.-J. Qi and J.-M. Zhou (National Institute of Biological Sciences, Beijing) for kindly providing us with the seeds of Arabidopsis mutants, H.-S. Dong (Nanjing Agricultural University, China) for the rifampicin-resistant pathogen Pseudomonas syringae pv. tomato DC3000 and Arabidopsis ecotype Col-0 expressing bacterial NahG, and P. A. H. M. Bakker (Utrecht University, The Netherlands) for P. fluorescens WCS417r. This research was supported by the National Natural Science Foundation of China (no. 30971956), the Natural Science Foundation of Jiangsu Province (no. BK2009310), and the Special Fund For Agro-Scientific Research In The Public Interest (no. 200903052).

\section{LITERATURE CITED}

Ahn, I.-P., Lee, S.-W., and Suh, S.-C. 2007. Rhizobacteria-induced priming in Arabidopsis is dependent on ethylene, jasmonic acid, and NPR1. Mol. Plant-Microbe Interact. 20:759-768.

Benhamou, N., and Belanger, R. R. 1998. Benzothiadiazole-mediated induced resistance to fusarium oxysporum $\mathrm{f}$. sp. radicis-lycopersici in tomato. Plant Physiol. 118:1203-1212.

Benhamou, N., Kloepper, J. W., Quadt-Hallman, A., and Tuzun, S. 1996. Induction of defense-related ultrastructural modifications in pea root tissues inoculated with endophytic bacteria. Plant Physiol. 112:919-929.

Bleecker, A. B., Estelle, M. A., Somerville, C., and Kende, H. 1988. Insensitivity to ethylene conferred by a dominant mutation in Arabidopsis thaliana. Science 241:1086-1089.

Bowling, S. A., Guo, A., Cao, H., Gordon, A. S., Klessig, D. F., and Dong, X. 1994. A mutation in Arabidopsis that leads to constitutive expression of systemic acquired resistance. Plant Cell 6:1845-1857.

Conrath, U., Pieterse, C. M., and Mauch-Mani, B. 2002. Priming in plantpathogen interactions. Trends Plant Sci. 7:210-216.

Conrath, U., Beckers, G. J., Flors, V., Garcia-Agustin, P., Jakab, G., Mauch, F., Newman, M.-A., Pieterse, C. M., Poinssot, B., Pozo, M. J., Pugin, A., Schaffrath, U., Ton, J., Wendehenne, D., Zimmerli, L., and Mauch-Mani, B. 2006. Priming: Getting ready for battle. Mol. PlantMicrobe Interact. 19:1062-1071.

Delaney, T. P., Uknes, S., Vernooij, B., Friedrich, L., Weymann, K., Negrotto, D., Gaffney, T., Gut-Rella, M., Kessmann, H., Ward, E., and Ryals, J. 1994. A central role of salicylic acid in plant disease resistance. Science 266:1247-1250.

Dos Santos, C. V., Letousey, P., Delavault, P., and Thalouarn, P. 2003. Defense gene expression analysis of Arabidopsis thaliana parasitized by Orobanche ramosa. Phytopathology 93:451-457.

Glazebrook, J. 2001. Genes controlling expression of defense responses in 
Arabidopsis-2001 status. Curr. Opin. Plant Biol. 4:301-308.

Guo, J. H., Wei, L. H., and Li, S. M. October 2007. The strain for biocontrol root-knot disease of vegetable. U.S. Patent 200710021376.0.

Hoagland, D. R., and Arnon, D. I. 1938. The water culture method for growing plants without soil. Calif. AEF Bull. 347:36-39.

Hossain, M. M., Sultana, F., Kubota, M., Koyama, H., and Hyakumachi, M. 2007. The plant growth-promoting fungus Penicillium simplicissimum GP17-2 induces resistance in Arabidopsis thaliana by activation of multiple defense signals. Plant Cell Physiol. 48:1724-1736.

Iriti, M., Rabotti, G., De Ascensao, A., and Faoro, F. 2003. Benzothiadiazole-induced resistance modulates ozone tolerance. J. Agric. Food Chem. 51:4308-4314.

Koornneef, A. and Pieterse, C. M. 2008. Cross talk in defense signaling. Plant Physiol.146:839-844.

Kunkel, B. N., and Brooks, D. M. 2002. Cross talk between signaling pathways in pathogen defense. Curr. Opin. Plant Biol. 5:325-331.

Lawton, K. A., Potter, S. L., Uknes, S., and Ryals, J. 1994. Acquired resistance signal transduction in Arabidopsis is ethylene independent. Plant Cell 6:581-588.

Leon-Reyes, A., Spoel, S. H., De Lange, E. S., Abe, H., Kobayashi, M., Tsuda, S., Millenaar, F. F., Welschen, R. A., Ritsema, T., and Pieterse, C. M. 2009. Ethylene modulates the role of NONEXPRESSOR OF PATHOGENESIS-RELATED GENES1 in cross talk between salicylate and jasmonate signaling. Plant Physiol. 149:1797-1809.

Millet, Y. A., Danna, C. H., Clay, N. K., Songnuan, W., Simon, M. D., Werck-Reichhart, D., and Ausubel, F. M. 2010. Innate immune responses activated in Arabidopsis roots by microbe-associated molecular patterns. Plant Cell 22:973-990.

Mur, L. A. J., Kenton, P., Atzorn, R., Miersch, O. and Wasternack, C. 2006. The outcomes of concentration-specific interactions between salicylate and jasmonate signaling include synergy, antagonism, and oxidative stress leading to cell death. Plant Physiol. 140:249-262.

Pieterse, C. M., van Wees, S. C., Hoffland, E., van Pelt, J. A., and van Loon, L. C. 1996. Systemic resistance in Arabidopsis induced by biocontrol bacteria is independent of salicylic acid accumulation and pathogenesis-related gene expression. Plant Cell 8:1225-1237.

Pieterse, C. M., van Wees, S. C., van Pelt, J. A., Knoester, M., Laan, R., Gerrits, H., Weisbeek, P. J., and van Loon, L. C. 1998. A novel signaling pathway controlling induced systemic resistance in Arabidopsis. Plant Cell 10:1571-1580.

Podile, A. R., and Laxmi, V. D. V. 1998. Seed bacterization with Bacillus subtilis AF 1 increases phenylalanine ammonia-lyase and reduces the incidence of fusarial wilt in pigeonpea. J. Phytopathol. 146:255-259.

Reuber, T. L., Plotnikova, J. M., Dewdney, J., Rogers, E. E., Wood, W., and Ausubel, F. M. 1998. Correlation of defense gene induction defects with powdery mildew susceptibility in Arabidopsis enhanced disease susceptibility mutants. Plant J. 16:473-485.

Ryu, C. M., Hu, C. H., Reddy, M. S., and Kloepper, J. W. 2003. Different signaling pathways of induced resistance by rhizobacteria in Arabidopsis thaliana against two pathovars of Pseudomonas syringae. New Phytol. 160:413-420.
Rudrappa T., Biedrzycki, M. L., Kunjeti, S. G., Donofrio, N. M., Czymmek, K. J., Pare, P. W., and Bais, H. P. 2010. The rhizobacterial elicitor acetoin induces systemic resistance in Arabidopsis thaliana. Commun. Integr. Biol. 3:130-138

Segarra, G., Van der Ent, S., Trillas, I., and Pieterse, C. M. J. 2009. MYB72, a node of convergence in induced systemic resistance triggered by a fungal and a bacterial beneficial microbe. Plant Biol. 11:90-96.

Silva, H. S. A., Romeiro, R. d. S., Macagnan, D., Halfeld-Vieira, B. D. A., Pereira, M. C. B., and Mounteerd, A. 2004. Rhizobacterial induction of systemic resistance in tomato plants: Non-specific protection and increase in enzyme activities. Biol. Control. 29:288-295.

Staswick, P. E., Su, W., and Howell, S. H. 1992. Methyl jasmonate inhibition of root growth and induction of a leaf protein are decreased in an Arabidopsis thaliana mutant. Proc. Natl. Acad. Sci. U.S.A. 89:6837-6840.

Szewczyk, B., Hoyos-Carvajal, L., Paluszek, M., Skrzecz, I., and Souza, M. L. 2006. Baculoviruses-re-emerging biopesticides. Biotechnol. Adv. 24:143-160

Van der Ent, S., Verhagen, B. W., Van Doorn, R., Bakker, D., Verlaan, M. G., Pel, M. J., Joosten, R. G., Proveniers, M. C., Van Loon, L. C., Ton, J., and Pieterse, C. M. 2008. MYB72 is required in early signaling steps of rhizobacteria-induced systemic resistance in Arabidopsis. Plant Physiol. 146:1293-1304

Van der Ent, S., Van Wees, S. C., and Pieterse, C. M. 2009. Jasmonate signaling in plant interactions with resistance-inducing beneficial microbes. Phytochemistry 70:1581-1588.

Van Loon, L. C., and Van Strine, E. A. 1999. The families of pathogenesisrelated proteins, their activities, and comparative analysis of PR-1 type proteins. Physiol. Mol. Plant Pathol. 55:85-97.

Van Loon, L. C., Bakker, P. A., and Pieterse, C. M. 1998. Systemic resistance induced by rhizosphere bacteria. Annu. Rev. Phytopathol. 36:453-483.

Van Oosten, V. R., Bodenhausen, N., Reymond, P., Van Pelt, J. A., Van Loon, L. C., Dicke, M., and Pieterse, C. M. 2008. Differential effectiveness of microbially induced resistance against herbivorous insects in Arabidopsis. Mol. Plant-Microbe Interact. 21:919-930.

Van Wees, S. C., de Swart, E. A., van Pelt, J. A., Van Loon, L. C., and Pieterse, C. M. 2000. Enhancement of induced disease resistance by simultaneous activation of salicylate- and jasmonate-dependent defense pathways in Arabidopsis thaliana. Proc. Natl. Acad. Sci. U.S.A. 97:8711-8716.

Van Wees, S. C., Van der Ent, S., and Pieterse, C. M. 2008. Plant immune responses triggered by beneficial microbes. Curr. Opin. Plant Biol. 11:443-448.

Ward, E. R., Uknes, S. J., Williams, S. C., Dincher, S. S., Wiederhold, D. L., Alexander, D. C., Ahl-Goy, P., Métraux, J. P., and Ryals, J. A. 1991. Coordinate gene activity in response to agents that lnduce systemic acquired resistance. Plant Cell, 3:1085-1094.

Yedidia, I., Shoresh, M., Kerem, Z., Benhamou, N., Kapulnik, Y., and Chet, I. 2003. Concomitant induction of systemic resistance to Pseudomonas syringae pv. lachrymans in cucumber by Trichoderma asperellum (T-203) and accumulation of phytoalexins. Appl. Environ. Microbiol. 69:7343-7353. 